a beautiful Victorian house called Maudsley House, not named after the famous Henry but after his Australian great-nephew (also Henry) who was an important figure in bringing psychiatry out of the asylum and into respectable medicine in the 1920s.

Research in Australia is handicapped by some of the factors mentioned earlier. Sometimes it has proved difficult to fill chairs in the less populous states. It is difficult to generate a 'critical mass' of researchers in one place and it may be that endeavours have been too thinly spread across too many areas. Grants are hard to get; in $1980-1983$ only $0.8 \%$ of National Health and Medical Research Council funding went to psychiatric projects. However, the quality of research in most university departments is very high. There are many people with imagination, intellect, flair and energy. Even though the distances between capital cities are great, there is a warm camaraderie and much mutual assistance across the Australian research community seen to advantage, for example, at annual meetings of the Australian Society for Psychiatric Research.
I seem to have dwelt to a large degree on negative aspects of psychiatry in Australia, probably because these occupy much of one's thoughts in one's attempts continually to make improvements. There are many positive aspects as well. In a comparatively flexible system as exists here, there is an enormous potential for innovation and growth, whilst avoiding, one hopes, the mistakes made previously elsewhere. The calibre of recruits to psychiatry is very high nowadays and the population of the College is getting proportionally younger and probably more energetic. Salaries, even in the state sector, are high. Warring factions in psychiatry are less evident here than in many other places and there is a sense of pulling together, perhaps somewhat fancifully construed as a remnant of the pioneering spirit of the past. There are enormous spaces to be filled and room for the marks of many to be impressed upon the psychiatric landscape. And Australian 'mateship' is not a myth; I was on first name terms with my bank manager on our first meeting and at the first conference $I$ attended here, name tags did not display surnames.

\section{Owner Occupied Accommodation for Psychiatric Patients}

The charity Good Practices in Mental Health (GPMH) 380-384 Harrow Road, London W9 is asking MPs and Senior Civil Servants to consider the establishment of a small group of projects where discharged psychiatric patients are given the opportunity to become owner occupiers instead of going into sub standard housing or to large hostel accommodation. GPMH argues that owner occupation is desirable because if community care is to open up choices for normal living, it does not make sense to restrict choices in tenure at a time when a majority of people either own or are buying their own homes. GPMH suggests that: mortgage financing be experimented with in a number of areas, particularly areas with relatively low cost housing; key health authorities and local authorities be encouraged to negotiate with building societies for the provision of mortgage finance; two or three experimental schemes be established in different areas of the country, using different systems of mortgage financing, with perhaps five to six people being rehoused in each area, and the results of these experimental schemes be evaluated, written up and disseminated to a wider audience.

\section{St Andrew's Hospital and the Broadcasting Complaints Commission}

The Broadcasting Complaints Commission adjudicated in February 1987 on a complaint from Dr Gavin Tennent, Medical Director, and the Governors of St Andrew's Hospital, Northampton, about a programme in the Checkpoint series broadcast on $\mathrm{BBCl}$ on 18 October 1984. The programme, entitled 'The Mind Benders', was about a form of treatment known as 'behaviour modification' as practised at St Andrew's and at Spyways Hospital in Dorset.

The Commission considered that the issue of the human rights of patients at St Andrew's was a legitimate subject for the programme to consider. In the Commission's view, however, the main impression left by the programme was that St Andrew's, because of the form of treatment practised in some of the units, was a terrible and fearful place. The evidence before the Commission did not substantiate this. The Commission concluded that in its presentation of St Andrew's and the treatment carried out there the programme was generally unfair to the complainants, although they considered that $\mathrm{Dr}$ Tennent was given sufficient opportunity in the programme to answer criticisms. Except on this point the Commission upheld the complaint. 